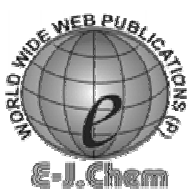

http://www.e-journals.net
ISSN: 0973-4945; CODEN ECJHAO

E-Journal of Chemistry

Vol. 5, No.3, pp. 648-651, July 2008

\title{
A Validated RP - HPLC Method for Simultaneous Estimation of Cefixime and Cloxacillin in Tablets
}

\author{
G.RATHINAVEL*, P.B. MUKHERJEE, J.VALARMATHY, \\ L.SAMUELJOSHUA ${ }^{\#}$, M.GANESH, T.SIVAKUMAR and T.SARAVANAN \\ Department of Pharmaceutical Chemistry, \\ Nandha College of Pharmacy, Erode-638 052, Tamilnadu, India. \\ Department of Pharmaceutical Chemistry, \\ "Padmavathi College of Pharmacy, Dharmapuri, Tamilnadu, India. \\ grvelsp@yahoo.com
}

Received 2 December 2007; Revised 22 January 2008; Accepted 12 February 2008

\begin{abstract}
This paper presents a RP-HPLC method for the simultaneous estimation of cefixime and cloxacillin in tablets. The process was carried out on $\mathrm{C}_{18}$ column ( $5 \mu \mathrm{m}, 25 \mathrm{~cm} \times 4.6 \mathrm{~mm}$, i.d) using phosphate buffer ( $\mathrm{pH} 5.0$ ), acetonitrile and methanol in the ratio 80:17: 3 respectively as a mobile phase at a flow rate of $2 \mathrm{~mL} / \mathrm{min}$. Wavelength was fixed at $225 \mathrm{~nm}$. The retention time of cefixime and cloxacillin was found to be 5.657 and $6.200 \mathrm{~min}$, respectively. The developed method is rapid and sensitive and it can be used for estimation of combination of these drugs in tablets.
\end{abstract}

Keywords: Cefixime, Cloxacillin, RP-HPLC Estimation.

\section{Introduction}

Cefixime, chemically designated as $(6 R, 7 \mathrm{R})-7$-[2-(2-amino-4-thiazolyl)glyoxylamido]-8-oxo3-vinyl-5-thia-1-azabicyclo[4.2.0]oct-2-ene-2-carboxylic acid,7-(Z)-[o-(carboxymethyl)-oxime] trihydrate is an antibiotic, and an oral third-generation cephalosporin. It is highly stable in the presence of beta-lactamase enzymes. Cloxacillin, chemically monosodium (2S, 5R, 6R) - 6 -[ $o$-(2 -chlorophenyl) - 5 -methyl - 4 -isoxazole carboxamido]-3,3-dimethyl -7-oxo- 4 thia -1- azabicyclo [3.2.0] heptane -2- carboxylate monohydrate is a semisynthetic antibiotic in the same class as penicillin. It used against staphylococci that produce beta-lactamase. From literature survey it was found that various methods have been reported for both the drugs individually but no HPLC methods were reported for such a combination in any type of pharmaceutical dosage form so far. The present work describes a simple, precise, and accurate reverse phase HPLC method for simultaneous estimation of Cefixime and Cloxacillin in combined dosage form. 


\section{Experimental}

Acetonitrile and methanol used were of HPLC grade and obtained from Merck Chemicals. All other chemicals used were of AR grade and obtained from Sd Fine Chemicals, Mumbai. Reference standards of cefixime and cloxacillin were obtained from Concept Pharmaceuticals Ltd., Aurangabad, India.

\section{Instrumentation}

Quantitative HPLC was performed on a isocratic HPLC of SHIMADZU prominence consisting of LC - 20AT liquid pump, manual with $20 \mu \mathrm{L}$ sample injection loop and SPD 20A UV-visible absorbance detector. The output - signal was monitored and integrated by Shimadzu spin chrome software.

\section{Chromatographic conditions ${ }^{3-5}$}

The process was carried out on $\mathrm{C}_{18}$ column $(5 \mu \mathrm{m}, 25 \mathrm{~cm} \times 4.6 \mathrm{~mm}$, i.d) using the mobile phase consisting of phosphate buffer ( $\mathrm{pH} 5.0)$, acetonitrile and methanol ${ }^{1,2}$ in the ratio $(80: 17: 3 \mathrm{v} / \mathrm{v})$ respectively at a flow rate of $2 \mathrm{~mL} /$ minutes. Wavelength was fixed at $225 \mathrm{~nm}$. The mobile phase was filtered through $0.2 \mu$ membrane filter and degassed.

\section{Preparation of solutions}

Standard solution of the pure drug was prepared by dissolving $100 \mathrm{mg}$ of cefixime trihydrate and $250 \mathrm{mg}$ of cloxacillin sodium in a $100 \mathrm{~mL}$ volumetric flask using $25 \mathrm{~mL}$ of methanol. Then the volume made up to the mark with the same solvent. Appropriate volume from this solution was further diluted to get appropriate concentration levels according to the requirement.

Twenty tablets were weighed the average weight was determined and these were powdered. Sample solution was then prepared by dissolving the powdered tablets equivalent to $100 \mathrm{mg}$ of cefixime and $250 \mathrm{mg}$ of cloxacillin in a $100 \mathrm{~mL}$ of volumetric flask. Then the drugs were dissolved by using $25 \mathrm{~mL}$ methanol and the volume was made up to the mark with methanol. $5 \mathrm{~mL}$ of this solution was further diluted to $25 \mathrm{~mL}$ with the same solvent.

$20 \mu \mathrm{L}$ of solution was injected into HPLC system to obtain chromatogram for standard drug solution and sample solution. Concentrations of cefixime and cloxacillin in the formulation were calculated by comparing AUC of the sample with that of the standard.

\section{Assay method}

With the optimized chromatographic conditions, a steady baseline was recorded, the mixed standard solution was injected and the chromatogram was recorded. The retention time of cefixime and cloxacillin was found to be 4.657 and $6.200 \mathrm{~min}$ respectively. This procedure was repeated for the sample solution obtained from the formulation (Table 1) and recovery studies (Table 2).

Table 1. Analysis of formulation

\begin{tabular}{ccccc}
\hline \multirow{2}{*}{ S.No } & Brands/ & Label amount, mg & \multicolumn{2}{c}{ Amount recovered*, mg } \\
\cline { 3 - 5 } & Manufactures & & Cefixime & Cloxacillin \\
\hline 1. & Formulation-1 & Cefixime 200 & $198.57 \pm 0.8203$ & $499.94 \pm 0.7637$ \\
2. & Formulation-2 & Cloxacillin 500 & $199.70 \pm 0.7071$ & $505.72 \pm 0.0495$ \\
3. & Formulation-3 & & $198.35 \pm 0.1626$ & $502.40 \pm 0.5515$ \\
\hline
\end{tabular}

$*$ Each value is average of three determinations $\pm S D$ 


\section{Method validation 6,7}

Linearity and range of method was determined on standard solution by analyzing 80 to $120 \%$ of test concentration, and the calibration curve was plotted using AUC versus concentration of standard solution. Accuracy of method was ascertained by recovery study by adding a known amount of standard drug ( $\pm 20 \%$ of test concentration) to pre-analyzed sample and reanalyzing the samples by the proposed method. Precision was studied by analyzing five replicates of standard solution. Specificity was carried out by injecting placebo solution. Robustness of method was evaluated by performing the assay with variations in wavelength, $\mathrm{pH}$ and flow rate. The chromatographic parameters were also validated by system suitability studies (Table 3), which were carried out on freshly prepared standard stock solution.

\section{Results and Discussion}

The typical chromatogram obtained from the formulation is presented in Figure 1. The retention time for cefixime and cloxacillin was found to be 4.657 and 6.200 minutes respectively. Peaks were well resolved with resolution of 6.986 between the two drugs and were symmetrical in shape with asymmetry factor less than 2.00 . Linearity was observed in the concentration range of $160-240 \mu \mathrm{g} / \mathrm{mL}$ for cefixime and $400-600 \mu \mathrm{g} / \mathrm{mL}$ cloxacillin, with the correlation coefficient of 0.9998 for cefixime and 0.9999 for cloxacillin. Accuracy of the method was ascertained by recovery study $(n=3)$. The concentration of standard spiked to the sample was $80 \%-120 \%$ of the assay level. Recovery data form the study is reported in Table 2. The method was found to be accurate with percent recoveries between $99.99 \%$ and $102.24 \%$. There was good repeatability of proposed method with percentage RSD 0.69 for cefixime and 0.77 for cloxacillin. The results of specificity studies indicated no interference from excipients and mobile phase; the peak response was due to individual components only.

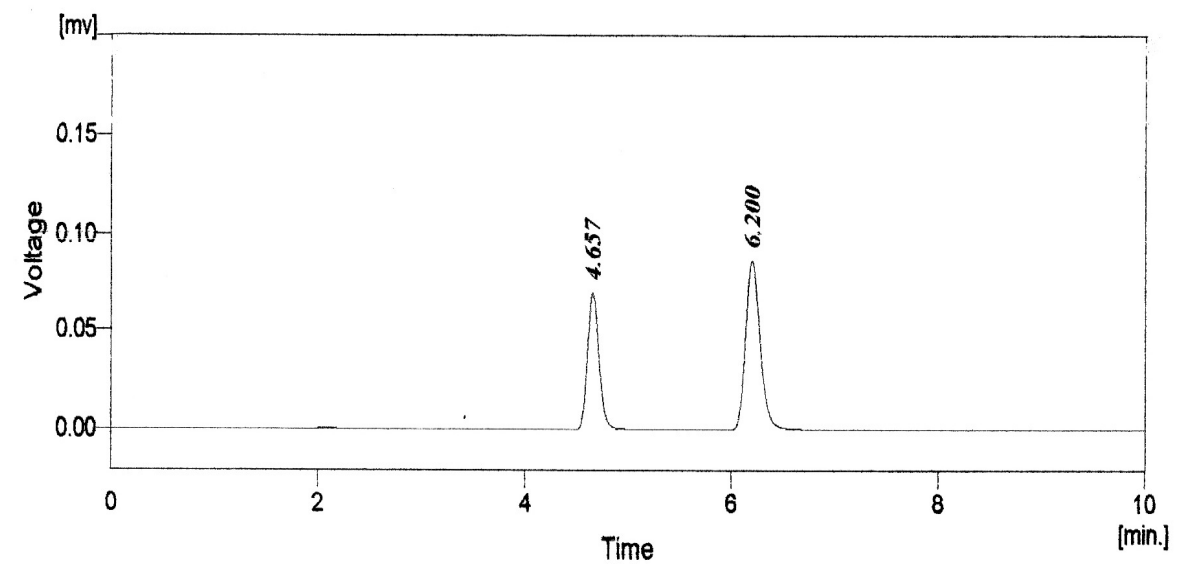

Figure 1. Typical chromatogram of the sample solution

Table 2. Recovery Studies

\begin{tabular}{|c|c|c|}
\hline \multirow{2}{*}{ Sample ID } & \multicolumn{2}{|c|}{ Statistical analysis Amount recovered*, mg } \\
\hline & Cefixime & Cloxacillin \\
\hline $\mathrm{S} 1-80 \%$ & Mean $*=98.99 \pm 0.1552$ & Mean $*=102.24 \pm 0.1950$ \\
\hline $\mathrm{S} 2-100 \%$ & Mean $*=99.45 \pm 0.1450$ & Mean $*=101.37 \pm 0.1007$ \\
\hline $\mathrm{S} 3-120 \%$ & Mean $*=100.21 \pm 0.2739$ & Mean $*=101.49 \pm 0.1916$ \\
\hline
\end{tabular}


Table 3. System suitability parameters

\begin{tabular}{lcc}
\hline \multicolumn{1}{c}{ Parameter } & Cefixime & Cloxacillin \\
\hline Calibration range, $\mu \mathrm{g} / \mathrm{mL}$ & $160-240$ & $400-600$ \\
Theoretical plates & 8826 & 10366 \\
$\begin{array}{l}\text { Resolution } \\
\text { Tailing factor }\end{array}$ & \multicolumn{2}{c}{6.986} \\
\hline
\end{tabular}

\section{Conclusion}

The proposed method was found to be simple, precise, accurate and rapid for determination of cefixime and cloxacillin from tablets. The mobile phase is simple to prepare and economical. The sample recoveries in all formulations were in good agreement with their respective label claims. Hence, it can be easily and conveniently adopted for routine analysis of cefixime and cloxacillin in tablets.

\section{Acknowledgements}

The authors are thankful to M/s. Concept Pharmaceuticals Ltd., Aurangabad, India for providing gift samples of Cefixime and Cloxacillin. The authors are grateful to Thiru V. Shanmugam, Chairman, Nandha College of Pharmacy, Erode-52, for providing facilities for the research work.

\section{References}

1. Joy A McAteer, Mark F Hiltke, Michael Silber B and Robert D Faulkener, Clinical Chemistry, 1987, 30, 1788-1790.

2. Rbeida O, Chiap P, Lubda D, Boos K S, Crommen J and Hubert Ph, J.Pharm.Biomed. Anal, 2005, 36, 961 -968.

3. Lambert K Sorensen, Lena K Snor, Tina Elkaer and Helga Hansen., J. Chromatography B: Biomed. Sci \& Applications, 1999,734(2), 307-318.

4. Kazue Takeba, Kenji Fujinuma, Tomoyuki Miyazaki and Hiroyuki Nakazawa, J.Chromatography A, 1998, 812(1-2), 205-211.

5. Vijay Kumar, Hemant Bhutani and Saranjit Singh, J. Pharm. Biomed. Anal, 2007, 43(2), 769-773.

6. ICH, Validation of Analytical Procedure: Methodology (Q2B), International Conference on Harmonization, IFPMA, Geneva 1996.

7. CDWE Reviewer guideline of Validation of Chromatographic Methods CMC Publishers Nov. 1994. 


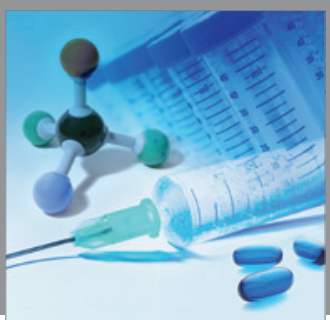

International Journal of

Medicinal Chemistry

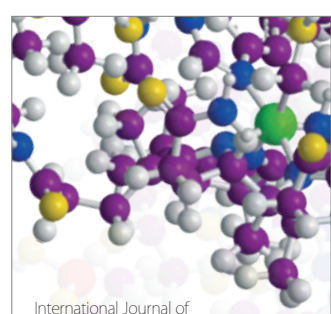

Carbohydrate Chemistry

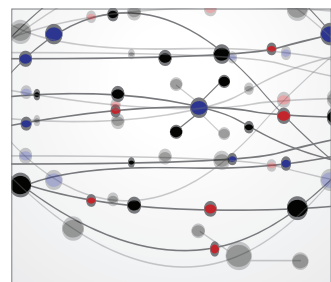

The Scientific World Journal
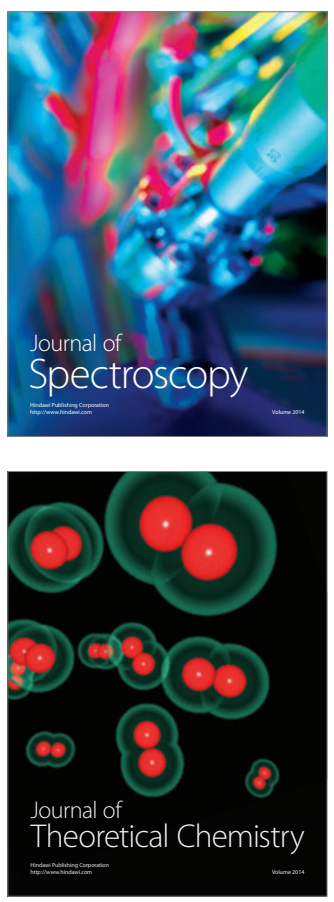
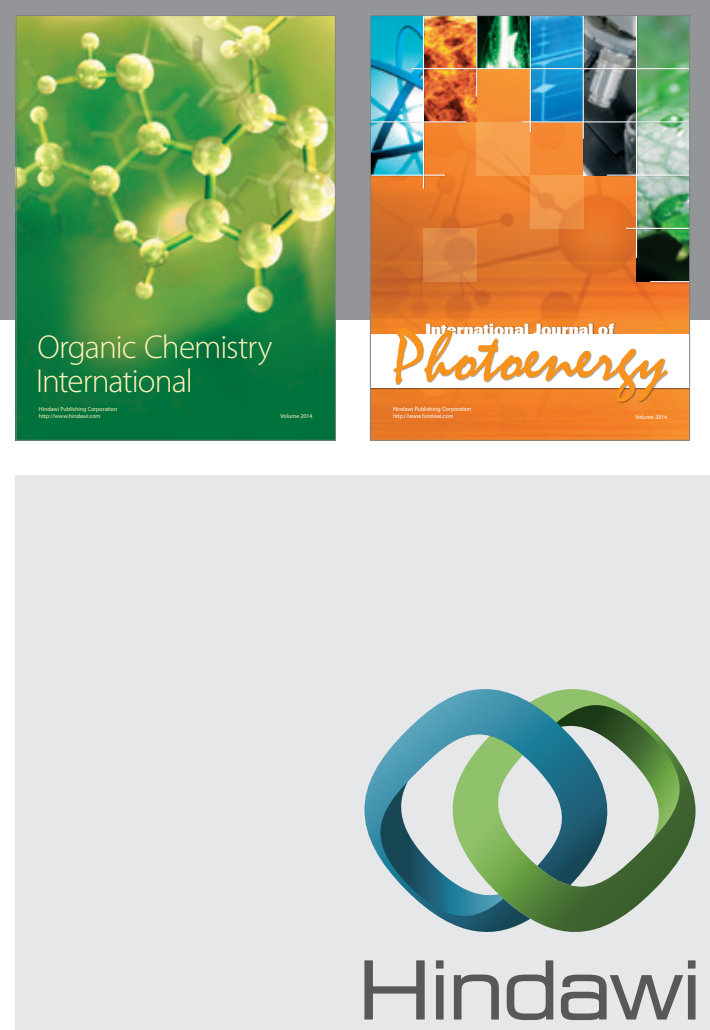

Submit your manuscripts at

http://www.hindawi.com
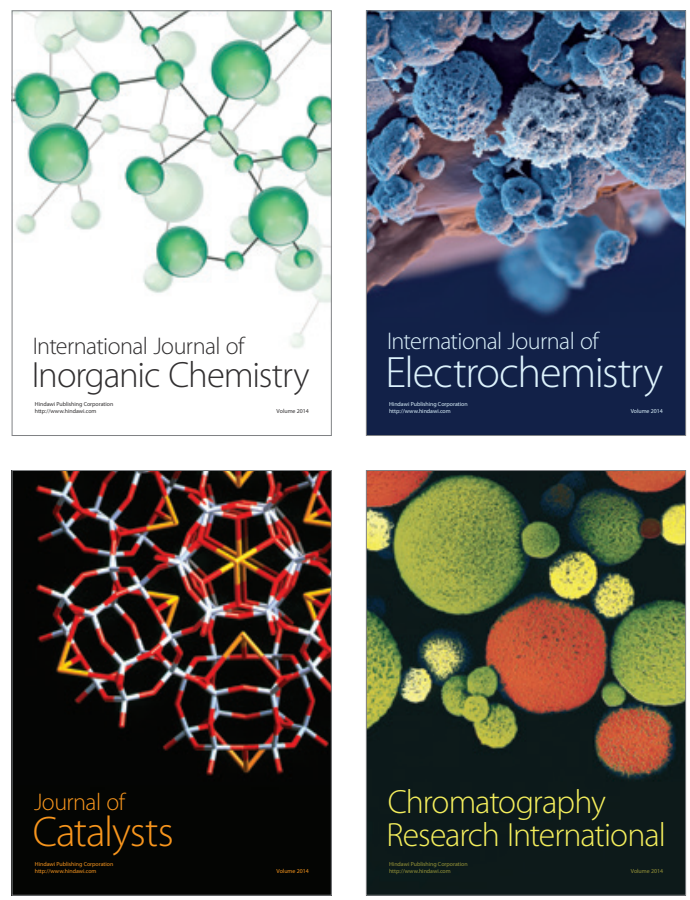
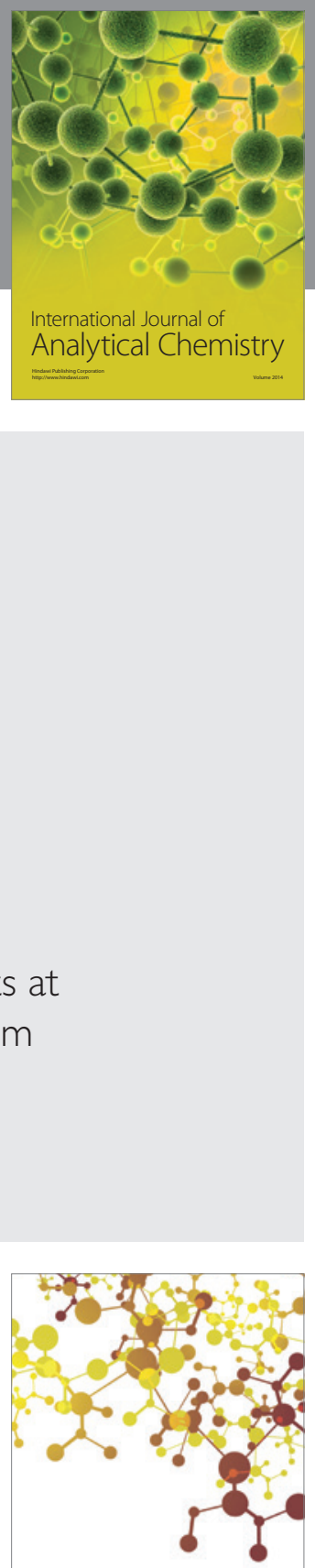

Journal of

Applied Chemistry
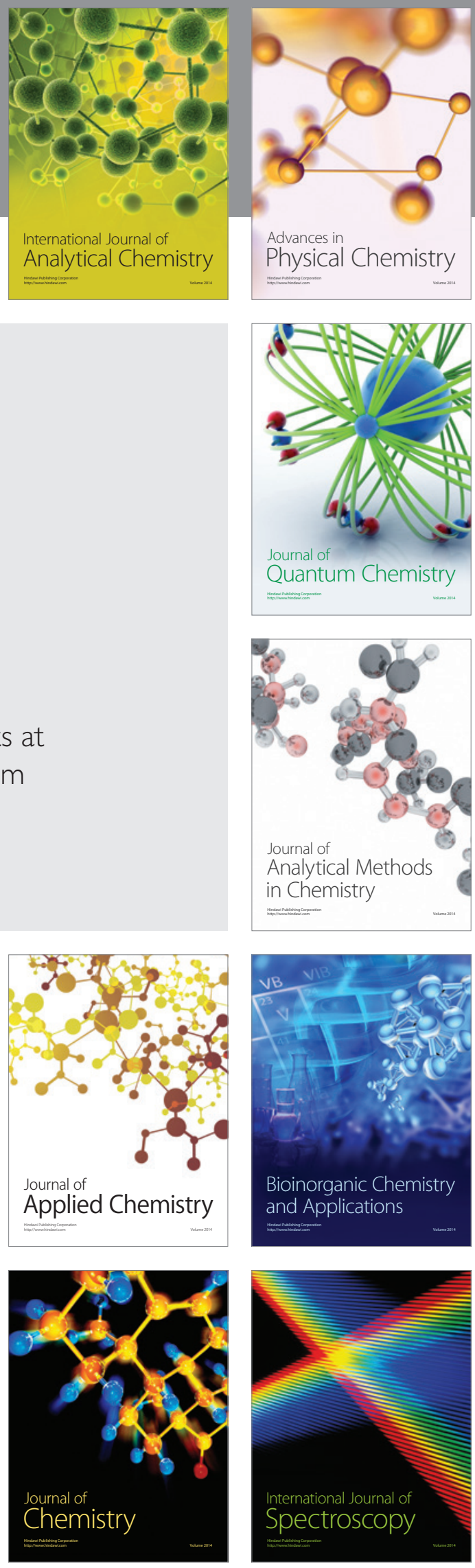